\title{
PERBANDINGAN TINGKAT STRESS KERJA ANTARA KARYAWAN TETAP DAN KARYAWAN OUTSOURCING BANK BRI WILAYAH YOGYAKARTA
}

\author{
Cinthia Annisa Vinahapsari \\ Manajemen, Universitas Teknokrat Indonesia \\ email: cinthiavinahapsari@teknokrat.ac.id
}

\begin{abstract}
ABSTRAK
Perekrutan karyawan melalui sistem outsourcing menghasilkan banyak pro dan kontra. Namun, implementasinya masih terus berlangsung. Perbedaan status pekerjaan di tempat kerja ternyata membawa pengaruh terhadap karyawan yakitu stres kerja. Penelitian ini bertujuan untuk menganalisis tingkat stress antara karyawan tetap dan karyawan outsoucing.. Data primer dikumpulkan dari 240 sampel responden (pegawai bank) dari empat cabang Yogyakarta. Penelitian ini menggunakan metode survei. Kuesioner menggunakan uji validitas isi, karena telah distandarisasi. Uji validitas menggunakan Alfa Cronbach dengan nilai> 0,7. Untuk mengetahui apakah ada perbedaan nyata antara karyawan tetap dan outsoucing karyawan pada tingkat stres dilakukan analisis perbedaan dua mean, t-test dengan menggunakan SPSS. Hasil penelitian menujukkan adanya terdapat perbedaan signifikan tingkat stress (role ambiguity, role conflict, dan environmental stressor) antara peekrja tetap dan pekerja outsourcing di Bank BRI Wilayah Yogyakarta.
\end{abstract}

Kata kunci: Stess kerja, Pekerja tetap, Pekerja outsoucing

\section{PENDAHULUAN}

\section{Latar Belakang Masalah}

Stres sudah menjadi bagian hidup yang tidak bisa dihindari lagi, begitu juga di dunia kerja. Adanya gangguan fisik dan mental akibat tekanan yang berasal dari dalam atau dari luar tempat kerja membuat karyawan menjadi stres.

Stres kerja adalah salah satu masalah paling serius yang hampir sebagian besar karyawan pernah mengalaminya. Stres kerja dapat dialami oleh siapa pun dan tidak memandang posisi, usia maupun jenis kelamin seseorang. Oleh karena itu, stress kerja perlu mendapat perhatian khusus dari perusahaan.

Berdasarkan penelitian sebelumnya diketahui bahwa stress kerja dapat berdampak buruk pada karyawan. Ganster \&
Schaubroeck (1991) $)^{[1]}$, mengemukakan bahwa stress kerja berdampak negatif pada kesehatan karyawan. Bashir (2010) ${ }^{[2]}$ dan Ravinarayana (2016) ${ }^{[3]}$ mengemukakan bahwa stress kerja dapat menurunkan kinerja kerja (job performance) karyawan. Tidak hanya itu, stres kerja dapat mempengaruhi kebahagiaan (happiness) karyawan (Naseem, 2018) ${ }^{[4]}$. Selanjutnya, Cheng (2014) ${ }^{[5]}$ mengemukakan stres kerja berkorelasi negatif dengan kepuasan kerja karyawan. Yu, et. al (2015) ${ }^{[6]}$ stress kerja berkorelasi signifikan dengan burnout.

Berdasarkan uraian diatas, maka dapat dikemukakan bahwa stres kerja dapat berdampak negatif pada karyawan. Mengingat pentingnya keberadaan karyawan di dalam suatu perusahaan, maka kesehatan karyawan sangat perlu diperhatikan. Karyawan merupakan aset 
terpenting dalam perusahaan dan bahkan diyakini dapat menentukan keberhasilan perusahaan. Oleh karenanya karyawan perlu dijaga, dan dikelola dengan baik.

Karyawan, dalam suatu perusahaan yang bergerak di bidang jasa layanan seperti perbankan, merupakan ujung tombak dalam melakukan layanan kepada para nasabahnya. Kualitas kinerja karyawan sangat menentukan mutu layanan yang akan diberikan kepada nasabahnya. Oleh karenanya, dalam bidang perbankkan kualitas kinerja prima menjadi prioritas kinerja yang dipersyaratkan bagi pekerjanya..

Kendati sistem outsourcing banyak melahirkan pro dan konta, tetapi penerapannya masih saja terus berlangsung hingga saat ini. Berdasarkan hasil penelurusan, menunjukkan bahwa terdapat kesenjangan antara pekerja tetap dan pekerja outsourcing. Pekerja outsourcing cenderung merasa kurang nyaman dalam bekerja, karena statusnya yang bersifat sementara dalam perusahaan tersebut. Pekerja outsourcing bekerja berdasarkan sistem outsoucing dalam kurun waktu tertentu berdasarkan kesepakatan, sehingga sewaktu waktu dapat diputus hubungan kerjanya secara sepihak terkait kualitas kinerjanya. Perbadaan status ditempat kerja khawatirkan dapat mempengaruhi prestasi kerja antara pekerja tetap dan pekerja outsourcing. Menurut Handoko (2001) ${ }^{[7]}$, ada banyak faktor yang dapat mempengaruhi prestasi kerja seorang pekerja, salah satunya adalah stress kerja.

Mengingat keberadaan karyawan di dalam perusahaan sangat penting dan juga hampir sebagian besar karyawan pernah mengalaminya stres kerja, maka penelitian ini dilakukan. Penelitian ini bertujuan untuk mecari perbedaan yang nyata antara pekerja tetap dan pekerja outsourcing dalam hal tingkat sress. Inilah yang membedakan penilitian ini dengan penelitian sebelumnya.

\section{LANDASAN TEORI}

\section{Outsourcing}

\section{A. Pengertian Outsourcinng}

Berdasarkan

hukum

ketenagakerjaan di Indonesia, outsourcing diartikan sebagai alih daya. Di Indonesia, sistem outsourcing diatur dalam UU Ketenagakerjaan No. 13 Tahun 2003 (pasal 64, 65, dan 66).

\section{B. Peran Outsourcing}

Outsourcing memiliki peranan yang sangat penting dalam mendukung kinerja organisasi dan efisiensi perusahaan. Hal ini dikarenakan perusahaan belum tentu mampu mencukupi tenaga kerja secara keseluruhan sehingga diperlukan adanya tenaga outsourcing yang dapat mendukung dari kinerja organisasi. Belcourt $(2006)^{[8]}$ menjelaskan peran outsourcing di dalam managemen perusahaan.

"Outsourcing is promoted as one of the most powerful trends in human resources management. The rationale for outsourcing $H R$ functions includes financial savings, an increased ability to focus on strategic issues, access to technology and specialized expertise, and an ability to demand measurable and improved service levels"

\section{Tujuan Outsourcing}

Tujuan dikembangkan sistem outsourcing yaitu membagi resiko usaha. Bagian-bagian tertentu (pokok) dari rangkaian usaha perusahaan tetap dikerjakan oleh perusahaan tersebut, sedangkan bagian penunjang lainnya di outsource ke perusahaan lain. Selain itu, untuk membuat pekerjaan menjadi efisiensi dan efektifitas kerja karena menyediakan SDM terampil siap pakai.

\section{Stress Kerja}

\section{A. Definsi Stress Kerja}

The National Institute of Occupational Safety and Health (NIOSH) $(2019)^{[9]}$ mendefinisikan Stress kerja 
sebagai sebagai respons fisik dan emosional yang berbahaya yang muncul akibat adanya ketidaksesuaian dengan kemampuan, sumber daya, atau kebutuhan pekerja, dan berdampak pada kesehatan yang buruk dan bahkan cedera.

"Job stress can be defined as the harmful physical and emotional responses that occur when the requirements of the job do not match the capabilities, resources, or needs of the worker. Job stress can lead to poor health and even injury." (NIOSH)

Stres adalah kondisi dinamis di mana seorang individu dihadapkan dengan kesempatan, permintaan, atau sumber daya yang terkait dengan apa keinginan individu dan yang hasilnya dipandang untuk menjadi tidak pasti dan penting. (Robbin, et al., 2007) ${ }^{[10]}$.

\section{B. Penyebab Stress Kerja}

Hampir semua orang setuju bahwa stres kerja dihasilkan dari interaksi pekerja dan kondisi kerja. Namun, ada pandangan berbeda tentang pentingnya karakteristik pekerja dan kondisi kerja sebagai penyebab utama stres kerja.

Crampton, et. al. $(1995)^{[11]}$ mengemukakan bahwa stress bila tidak dicari solusinya, dapat berakumulasi negatif pada kehidupan seseorang. Hal ini dikarenakan individu tersebut tidak mampu mengatasi dan mengendalikan stresnya.

\section{Akibat dari Stress Kerja}

Robbins \& Judge (2013) ${ }^{[12]}$ mengemukakan bahwa individu yang sedang mengalami stres akan menunjukan gejala-gejala sebagai berikut: a) Fisiologi b) Psikologis c) Perilaku

\section{Cara Mengatasi Stres Kerja}

Robbins \& Judge $(2013)^{[12]}$, berpendapat cara mengatasi stres dapat dilakukan dengan dua pendekatan yaitu pendekatan individu dan pendekatan organisasi: a) Pendekatan individu b) Pendekatan organisasi.

\section{METODELOGI}

\section{A. Populasi dan Sampel}

Populasi dalam penelitian ini adalah pekerja Bank BRI Wilayah Yogyakarta. Teknik pengambilan sampel dilakukan dengan cara convinience sampling yaitu para pekerja tetap dan outsoucing yang sedang berada di ruang kerja mereka pada saat penyebaran kuestioner. Jumlah populasi yaitu 240 pekerja.

\section{B. Lokasi Penelitian}

Penelitian dilakukan di Bank BRI Wilayah Yogyakarta (BRI Cabang Cik Ditiro, BRI Cabang Sleman, BRI Cabang Muntilan, dan BRI Cabang Magelang).

\section{Teknik Pengumpulan Data}

Data primer dijaring melalui: kuesioner, wawancara, dan observasi. Sedangkan data sekunder dijaring melalui dokumentasi. Kuesioner disusun berdasarkan tujuan penelitian terkait tingkat stess antara pekerja tetap dan pekerja outsoucing. Wawancara dilakukan secara langsung pada pekerja tetap dan pekerja outsoucing BRI Wilayah Yogyakarta. Dokumentasi dilakukan untuk melengkapi data dari hasil wawancara dan pengamatan. Bentuk dokumentasi berupa foto-foto, rekaman suara, rekaman gambar, dan data yang relevan dengan penelitian.

\section{Instrumen Penelitian}

Variabel stress dikukur dengan instrumen yang dikembangkan oleh Ivancevich dan Matteson (1988) ${ }^{[13]}$ yang terdiri dari 27 item, yaitu Role ambiguity (5 item), Role conflict (5 item), Upper stressor (3 item), Co-worker stressor (3 item), Environmental stressor (6 item), dan Work load (5 item). Respon dari responden diukur dalam skala Likert, dimulai dari skala 1 untuk "Sangat Tidak Setuju" dan 5 untuk "Sangat Setuju". 


\section{E. Metode Analisis Data}

Dalam penelitian ini tidak dilakukan uji validitas konstruk (construct validity), karena kuesioner yang digunakan sudah terstrandarisasi. Uji validitas dilakukan hanya sebatas validitas isi (content validity). Untuk menetapkan reliable atau tidaknya suatu pertanyaan, dilihat dari Cronbach's Alpha. Reliabilitas kurang dari 0,6 adalah kurang baik, sedangkan 0,7 dapat diterima dan diatas 0,8 adalah baik.

\section{F. Analisis Perbedaan Dua Mean, $t$-test.}

Analisis ini bertujuan mencari ada tidaknya perbedaan yang nyata antara pekerja tetap dan pekerja outsourcing dalam hal tingkat sress. Ada atau tidaknya perbedaan tersebut didasarkan pada distribusi perbedaan mean dari kedua macam sampel yang diteliti. Utntuk mengetahu beda atau tidaknya mean dari kelompok sampel yang ada, maka dugunakan t-test dengan menggunakan SPSS.

\section{ANALISIS DATA}

\section{A. Hasil Uji Beda Dua Mean}

Tabel 1.1. Hasil Uji Beda Mean

\begin{tabular}{|l|c|c|c|}
\hline $\begin{array}{l}\text { Tipe } \\
\text { Pekerja }\end{array}$ & \multicolumn{3}{|c|}{ Stress } \\
\hline & Mean & t & Sig \\
\hline Tetap & 2,6446 & $-2,848$ & 0,005 \\
\hline Outsourcing & 2,8492 & -24 & \\
\hline
\end{tabular}

Hasil pengujian menunjukkan bahwa tingkat stress pekerja outsoucing $(x=2,8492)$ lebih tinggi secara signifikan dari pada pekerja tetap $(\mathrm{x}=2,6446) \quad(\mathrm{t}=-$ $2,848 ; \mathrm{p}=0,005)$.

\section{B. Perbedaan Tingkat Stress Pekerja Tetap dan Pekerja Outsoucing di BRI Wilayah Yogyakarta}

Untuk menganalisis perbedaan secara lebih mendalam dimensi - dimensi setiap variabel, dilakukan uji beda dua mean pada setiap dimensi masing-masing variabel. Tabel berikut menunjukkan hasil uji beda dua mean dimensi - dimensi pada variabel stress.

Tabel 1.2: Hasil Uji Beda Dua Mean Dimensi Variabel Stress

\begin{tabular}{|l|c|c|c|c|}
\hline \multicolumn{1}{|c|}{$\begin{array}{c}\text { Tipe } \\
\text { Pekerja }\end{array}$} & Tetap & $\begin{array}{c}\text { Outsou } \\
\text { rcing }\end{array}$ & t & Sig \\
\cline { 2 - 5 } & Mean & Mean & \\
\hline $\begin{array}{l}\text { Dimensi } \\
\text { Stress }\end{array}$ & & & & \\
\hline $\begin{array}{l}\text { Role } \\
\text { Ambiguity }\end{array}$ & 2,5480 & 2,3017 & 2,567 & 0,012 \\
\hline $\begin{array}{l}\text { Role } \\
\text { Conflict }\end{array}$ & 2,3730 & 2,9593 & - & 0,000 \\
\hline $\begin{array}{l}\text { Co-worker } \\
\text { Stressor }\end{array}$ & 2,0870 & 2,0676 & 0,187 & 0,852 \\
\hline $\begin{array}{l}\text { Upper } \\
\text { stressor }\end{array}$ & 3,3530 & 3,2305 & 1,322 & 0,189 \\
\hline $\begin{array}{l}\text { Environmen } \\
\text { tal Stressor }\end{array}$ & 2,5432 & 3,1697 & - & 0,000 \\
\hline $\begin{array}{l}\text { Work } \\
\text { Load }\end{array}$ & 3,0440 & 3,1424 & - & 0,122 \\
\hline
\end{tabular}

Hasil pengujian menunjukkan terdapat tiga dimensi variabel stress yang memiliki perbedaan signifikan, yaitu dimensi role ambiguity, role conflict, dan environmental stressor.

\section{Perbedaan Role Ambiguity Pekerja Tetap dan Pekerja Outsoucing di BRI Wilayah Yogyakarta}

Berdasarkan pengujian terhadap 240 pekerja tetap dan outsoucing, diketahui bahwa pekerja outsourcing mememiliki persepsi role ambiguity $(\mathrm{x}=2,3017)$ lebih rendah signifikan dari pada pekerja tetap $(\mathrm{x}=2,5480)(\mathrm{t}=2,567 ; \mathrm{p}=0,012)$. Berdasarkan hasil wawancara yang mendalam terhadap pekerja outsourcing, tingkat role ambiguity pekerja outsourcing lebih tinggi dibandingkan pekerja tetap dikarenakan tidak adanya kejelasan menganai tugastugas dari pekerjaannya. Hal ini dipicu karena kurangnya pengalaman kerja. 


\section{Perbedaan Role Conflict Pekerja Tetap dan Pekerja Outsoucing di BRI Wilayah Yogyakarta}

Pekerja outsoucing memiliki persepsi role conflict $(\mathrm{x}=2,9593)$ lebih tinggi secara signifikan dari pada pekerja tetap $\quad(\mathrm{x}=2,3720) \quad(\mathrm{t}=-5365 ; \mathrm{p}=0,000)$. Berdasarkan hasil wawancara yang mendalam terhadap pekerja outsourcing, tingkat role conflict pekerja outsourcing lebih tinggi dibandingkan dengan pekerja tetap dikarenakan adanya perbedaan harapan dengan peran yang mereka jalankan. Perbedaan harapan ini mengakibatkan tekanan dari pemegang peranan untuk menunjukkan kinerja yang lebih baik antara satu dengan yang lainnya. Role conflict pada pekerjaan mengarah pada tingkah lau disfungsional dalam pekerjaan seperti ketidakpuasan kerja. Apabila hal ini dibiarkan, akan berpotensi menurunkan kinerja kerja (job performance) karyawan. Hal ini sejalan dengan pemikiran Ravinarayana (2016) ${ }^{[6]} \quad$ yang mengemukakan bahwa stress kerja dapat menurunkan kinerja kerja karyawan.

\section{E. Perbedaan Environmental Stressor Pekerja Tetap dan Pekerja Outsoucing di BRI Wilayah Yogyakarta}

Berdasarkan hasil pengujian menunjukkan bahwa pekerja outsoucing memiliki persepsi environmental stressor $(x=3,1697)$ lebih tinggi secara signifikan dari pada pekerja tetap $(\mathrm{x}=2,5432) \quad(\mathrm{t}=$ 6,122; $\mathrm{p}=0,000)$. Berdasarkan hasil wawancara yang mendalam terhadap pekerja outsourcing, tingkat role ambiguity pekerja outsourcing lebih tinggi dibandingkan pekerja tetap dikarenakan lingkungan tempat bekerja yang yang kurang kondusif. Adanya gap antara pekerja tetap dan pekerja outsourcing membuat karyawan outsourcing merasa kurang nyaman.

\section{KESIMPULAN}

Berdasarkan pembahasan, dapat ditarik kesimpulan beberapa kesimpulan diantaranya: Terdapat perbedaan signifikan tingkat stress (role ambiguity, role conflict, dan environmental stressor) antara pekerja tetap dan pekerja outsourcing di Bank BRI Wilayah Yogyakarta. Perbedaan tingkat stress pekerja dipengaruhi oleh beberapa faktor seperti ketidakjelasan peran antara pekerja tetap dan pekerja outsourcing (role ambiguity), lamanya masa kerja, pengalaman kerja, dan lingkungan kerja yang tidak kondusif.

\section{DAFTAR PUSTAKA}

${ }^{[1]}$ Ganster, Daniel. C., \& Schaubroeck, John. 1991. Work Stress and Employee Health. Journal of Management (J.O.M). Vol. 17. No. 2. Pages 235-271.

${ }^{[2]}$ Bashir, Usman., Ramay, Muhammad Ismail. 2010. Impact of Stress on Employees Job Performance. A Study on Banking Sector of Pakistan. International Journal of Marketing Studies. Vol. 2. No. 1. ${ }^{[3]}$ Ravinarayana, K.S., Ramakrishna, H. 2016. Impact Of Job Stress On Employee's Performance: An Empirical Study. Journal on management . Vol. 11. No. 1. Pages 611.

${ }^{[4]}$ Naseem, Khalida. 2018. Job Stress, Happiness and Life Satisfaction: The Moderating Role of Emotional Intelligence Empirical Study in Telecommunication Sector Pakistan. Journal of Social Sciences and Humanity Studies. Vol. 4. No.1. Pages 7-14.

${ }^{[5]}$ Cheng, Ching-Yu., Liou, Shwu$\mathrm{Ru}$.,Chang, Chia-Hao. 2015. Job stress and job satisfaction Among New Graduate Nurses During The First Year of Employment in Taiwan. International Journal of Nursing Practice. Vol. 21. No. 4. 
${ }^{[6]}$ Yu, Xiaobo. et. al. 2015. The Effect of Work Stress on Job Burnout Among Teachers: The Mediating Role of Selfefficacyal. Social Indicators Research. Vol. 122, No. 3. Pages 701-708.

${ }^{[7]}$ Handoko, Hani. 2001. Manajemen Personalia. Yogyakarta: BPFE.

${ }^{[8]}$ Belcourt, Monica. 2006. Outsourcing The Benefit and The Risks. Human Resource and Management. Vol. 16, No. 2, Pages 269-279.

${ }^{[9]}$ The National Institute of Occupational Safety and Health (NIOSH). 2019.

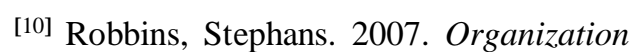
Bahaviour. Seventh Edition. A Simon \& SchusterCompany, Englewood Cliffs, New Jersey.07632.

${ }^{[11]}$ Crampton, Suzanne, M., Hodge, J.W., Mishra, J.M. 1995. Stress and stress management. Journal of Advance Management. Vol. 60. No. 3 Page 2.

${ }^{[12]}$ Robbins, Stephen P., \& Judge, Timothy A. (2013) . Organizational Behavior (Edition 15). New Jersey : Pearson Education.

${ }^{[13]}$ Ivancevich, J. M. \& Matteson, M. T. 1988. Stress Diagnostic Survey: Form A. Houston: FD Associates. 